\title{
Discrimination of Geographical Origin of Unroasted Kernels Argan Oil (Argania spinosa (L.) Skeels) Using Tocopherols and Chemometrics
}

\author{
Sara Elgadi $\left.{ }^{1}\right)^{1,2}$ Ahmed Ouhammou ${ }^{D},{ }^{1}$ Hamza Zine $\mathbb{D}^{1},{ }^{1}$ Nadia Maata, ${ }^{3}$ \\ Abderrahmane Aitlhaj $\mathbb{C}^{4},{ }^{4}$ Hassan El Allali, ${ }^{5}$ and Abderraouf El Antari $\mathbb{C}^{2}$ \\ ${ }^{1}$ Laboratory of Microbial Biotechnology, Agrosciences and Environment, Regional Herbarium 'MARK', \\ Faculty of Sciences-Semlalia, Cadi Ayyad University, BP. 2390. 40 000, Marrakech, Morocco \\ ${ }^{2}$ Laboratory of Agro. Food Technology and Quality, Regional Center for Agronomic Research of Marrakech, \\ National Institute of Agronomic Research (INRA), Marrakech, Morocco \\ ${ }^{3}$ Official Laboratory for Chemical Analysis and Research (LOARC), Casablanca, Morocco \\ ${ }^{4}$ National Agency for the Development of the Oasis and Argan Zones (ANDZOA), Agadir 80000, Morocco \\ ${ }^{5}$ The Interprofessional Federation of the Argan Sector, Agadir 80000, Morocco
}

Correspondence should be addressed to Sara Elgadi; sara.elgadi@ced.uca.ma

Received 28 August 2020; Revised 18 September 2021; Accepted 22 September 2021; Published 11 October 2021

Academic Editor: Alessandra Durazzo

Copyright $\odot 2021$ Sara Elgadi et al. This is an open access article distributed under the Creative Commons Attribution License, which permits unrestricted use, distribution, and reproduction in any medium, provided the original work is properly cited.

Valorisation of Argan oil requires the precise identification of different provenances markers. The concentration of tocopherol is regarded as one of the essential parameters that certifies the quality and purity of Argan oil. In this study, 39 Argan samples from six different geographical origins (Safi, Essaouira, Agadir, Taroudant, Tiznit, and Sidi Ifni) from the central west of Morocco were collected and extracted using cold pressing. The total tocopherol amount was found to range from 783.23 to $1,271.68 \mathrm{mg} / \mathrm{kg}$. Generally, $\gamma$-tocopherol has the highest concentration in Argan oil. It should also be noted that the geographical origin was found to have a strong effect on the amounts of all tocopherol homologues studied. Principal component analysis of tocopherol concentrations highlighted a significant difference between the different provenances. The content of tocopherol has also been found to be strongly influenced by the distance from the coast and altitude, whereas no significant effect was found regarding other ecological parameters. The prediction ability of the LDA models was $87.2 \%$. The highest correct classification was revealed in coastal provenances $(100 \%)$, and the lowest values were from the continental ones $(71.4 \%)$. These results provide the basis for determining the geographical origins of Argan oil production with well-defined characteristics to increase the product's value and the income of local populations. In addition, this study provides a very promising basis for developing Argan varieties with a high content of tocopherol homologues, as well as contributing to the traceability and protection of Argan oil's geographical indication.

\section{Introduction}

Argan (Argania spinosa (L.) Skeels) is an endemic plant that represents the only species of genus Argania and the family of Sapotaceae in North Africa. Currently, the Moroccan Argan forest spans the fertile Souss Valley, the Anti-Atlas mountain range, and the coastal regions between Safi and Agadir [1]. This area exhibits high plant diversity and endemism [2]. The Argan forest was recognised in 1998 as a UNESCO biosphere reserve (Man and the Biosphere
Reserve) [3], and it significantly contributes to the economic and social development in Morocco and sometimes even represents the only source of income for the local population [4]. Argan kernels provide a precious oil that is rich in antioxidant compounds, such as saponins and tocopherols [5], as well as fatty acids [6] and sterols [7].

Vitamin E is a vitamin of eight isomers: four tocopherols and four tocotrienols [8]. Tocopherols are the isomers with the greatest biological activity [9]. For example, $\alpha$-tocopherol (5,7,8-trimethyltocol) is effective against ischemic liver 
cell damage thanks to its free radical scavenging properties [10]. Moreover, $\gamma$-tocopherol (7,8-dimethyltocol) has been found to have an effect on various types of tumours, even more powerful than $\alpha$-tocopherol, $\beta$-tocopherol $(5,8$ dimethyltocol), and $\delta$-tocopherol (8-methyltocol) [11]. Tocopherols and tocotrienols are present in fruits and plant seeds [12]. Therefore, fixed oils are a major source of tocopherols [13]. Several studies have compared tocopherol levels in Argan oil and other oils such as olive oil and prickly pear seed oil [14], The results showed that Argan oil has very high concentrations of tocopherols, especially the $\gamma$-tocopherol homologue [15]. In general, the presence of tocols prevents lipid oxidation and, hence, maintains the quality and shelf life of oils [16].

Argan oil plays a potential role in the prevention of several diseases [17], including cancer [18], and has lipidlowering and anti-oxidant properties [19]. These pharmacological properties can be attributed to its high content of tocopherols, especially $\gamma$-tocopherol [8]. Argan oil is richer in linoleic acid than olive oil $(5.4 \%-13.2 \%$ compared to $32.3 \%-34.1 \%$, respectively) [6]. The total tocopherol content is considered a purity criterion by the Moroccan 08.5.090 standard for Argan oil, with an established quantity that should fluctuate between 600 and $900 \mathrm{mg} / \mathrm{kg}$ of oil [20]. Gharby et al. [21] reported that the tocopherol content ranges between 675 and $871 \mathrm{mg} / \mathrm{kg}$ of oil, but a higher range (687.4-1,068 mg/kg of oil) has been observed by Aithammou et al. [22]. This variability in tocopherol concentration can be attributed to many factors, such as the climate [23], variety [24], extraction method [25], storage conditions [26], fruits form [27], and fruits maturity [28].

The genotype has an important impact on oil yield and composition [29]. In the case of apricots (Prunus armeniaca L.), the genetic factor influences the composition of tocopherol homologues [29]. Furthermore, the variability of tocopherol composition in various seed oils recovered from the by-products of the apple industry has been attributed to cultivars [30]. Using SRAP and REMAP markers, strong genetic differentiation has been found within Argan populations [31]. A. spinosa forests have been considered as "climax" [32]. This state of equilibrium has been reached by spontaneous vegetation under the action of the natural environment, excluding direct or indirect human action [33].

The consumption of cold-pressed oils has increased in recent years [34]. The global Argan oil market is expected to grow at a revenue-based compound annual growth rate of $10.8 \%$ between 2020 and 2027 [35]. Such development requires more control to protect the consumer and the producer from fraud. In fact, several marketing and promotional strategies aimed to relate food products to their geographical origin. European Union legislation, for example, allows the reservation of geographical designations for food products, such as Protected Designations of Origin (PDO) and protected geographical indications (PGI) [36]. The combination of chemical composition and chemometric tools such as linear discriminant analysis (LDA) [37] and partial least squares discriminant analysis (PLS-DA) [23] has been used for determining authenticity and quality control of Argan oil. However, there is a lack of studies focussing on the relationship between the tocopherol concentration in Argan oil and geographical origin [22].

The aim of this study was to determine the tocopherols concentration from six Moroccan provinces: Safi, Essaouira, Agadir Ida Outanane, Taroudant, Tiznit, and Sidi Ifni, associated with the chemometric technique LDA, to classify Argan oil according to its geographical origin. This may constitute the basis for geographical origin certification that helps protect the consumer and the producer from fraud and increase the value of Argan oil in the world market. In addition, it can provide a database for updating the Moroccan standard on Argan oil.

\section{Materials and Methods}

2.1. Plant Material. Argan plants naturally reproduce by seeding, which is the very reason for their great diversity. However, this study focussed on the potential for industrial production representative of a specific environment, very close to that intended for industrial production by local women's cooperatives. To this end, a maximum of trees contributed to the constitution of our batches of samples. Therefore, Argan fruits from natural populations were collected at full maturity from adult trees from six different geographical origins in the central west of Morocco: Safi (for the first time), Essaouira, Agadir, Taroudant, Tiznit, and Sidi Ifni (Figure 1).

This area is characterized by a semiarid to arid climate [1]. Temperature and rainfall data were collected from different weather stations for the period from 1989 to 2019 (Table 1). A total of 39 samples were collected between August and November 2018. After sun drying for two weeks, $20 \mathrm{~kg}$ of fruit for each studied point was depulped and crushed manually between two stones, yielding between 800 and $1,500 \mathrm{~g}$ of kernels for each sample. The kernels were then tightly closed by vacuum to eliminate oxidation until the extraction process. The moisture within the Argan kernels was measured using the international standard ISO 665 to be in the range from $3 \%$ to $5 \%$.

2.2. Oil Extraction. To allow the extrapolation of the results to potential production at the level of cooperatives and local industries, the extraction method used was identical to that used to produce Argan oil in Morocco. For this purpose, unroasted kernels were cold-pressed using an oil press (Komet CA59 G; IBG Monforts Oekotec GmbH Co. KG, Mönchengladbach, Germany). The screw speed was maintained at $30 \mathrm{rpm}$, and the temperature of the heated press was fixed at $50^{\circ} \mathrm{C}$. The temperature of the obtained oil was $20^{\circ} \mathrm{C}$. Then, once the oil was decanted, it was preserved in $250 \mathrm{~mL}$ dark glass bottles in a refrigerator $\left(\right.$ at $\left.4^{\circ} \mathrm{C}\right)$ filled with nitrogen to avoid oxidation. The oil yield varied between $48.43 \%$ and $50.67 \%$.

2.3. Physicochemical Quality Parameters. Free acidity (expressed as percentage oleic acid), spectrophotometric UV indices $K_{232}$ and $K_{270}$, peroxide value given as 


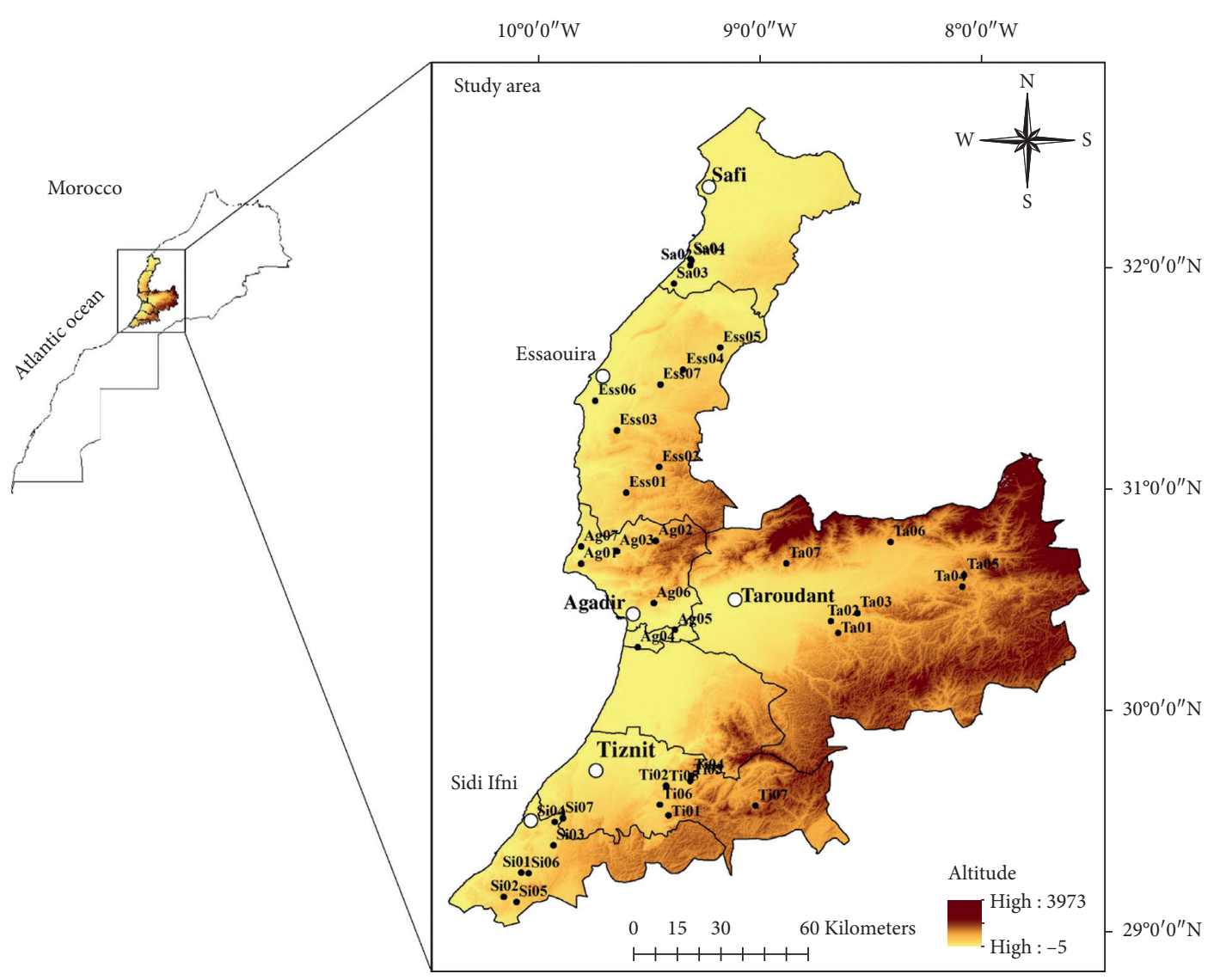

Figure 1: Altitude of sampling provenances and localisation of Argan samples.

TABle 1: Geographical parameters of the six sampled provenances of argan trees.

\begin{tabular}{lcccccccc}
\hline Provenance & Code & Sample size & Latitude & Longitude & Altitude (masl) & $\begin{array}{c}\text { Temperature min-max } \\
\left({ }^{\circ} \mathrm{C}\right)\end{array}$ & $\begin{array}{c}\text { Rainfall } \\
(\mathrm{mm} / \text { year })\end{array}$ & $\begin{array}{c}\text { Distance from coast } \\
(\mathrm{km} . \mathrm{a} . \mathrm{c} . \mathrm{f})\end{array}$ \\
\hline Safi & SA & 4 & $32^{\circ} 02^{\prime} \mathrm{N}$ & $9^{\circ} 18^{\prime} \mathrm{W}$ & 112 & $13.15-29.60$ & 320.36 & 5.57 \\
Essaouira & $\mathrm{ES}$ & 7 & $30^{\circ} 59^{\prime} \mathrm{N}$ & $9^{\circ} 36^{\prime} \mathrm{W}$ & 138 & $13.50-26.40$ & 292.17 & 19.77 \\
Agadir & $\mathrm{AG}$ & 7 & $30^{\circ} 22^{\prime} \mathrm{N}$ & $9^{\circ} 23^{\prime} \mathrm{W}$ & 103 & $12.92-24.55$ & 264.40 & 22.27 \\
Taroudant & TA & 7 & $30^{\circ} 26^{\prime} \mathrm{N}$ & $8^{\circ} 33^{\prime} \mathrm{W}$ & 592 & $11.42-31.20$ & 210.37 & 106.86 \\
Tiznit & TI & 7 & $29^{\circ} 41^{\prime} \mathrm{N}$ & $9^{\circ} 19^{\prime} \mathrm{W}$ & 497 & $12.70-26.31$ & 205.47 & 62.54 \\
Sidi Ifni & SI & 7 & $29^{\circ} 23^{\prime} \mathrm{N}$ & $9^{\circ} 56^{\prime} \mathrm{W}$ & 349 & $13.44-28.70$ & 155.92 & 21.95 \\
\hline
\end{tabular}

Masl: meters above sea level; km.a.c.f: $\mathrm{km}$ as the crow flies.

milliequivalents of active oxygen per kilogram of oil (meq $\mathrm{O}_{2} / \mathrm{kg}$ ), and oil content (\%) were determined according to ISO 660 (2009) [38], ISO 3656 (2002) [39], ISO 3960 (2007) [40], and ISO 659 (2009) [41], respectively.

2.4. Tocopherols Composition. According to ISO 9936 [42], $1 \mathrm{~g}$ of Argan oil was dissolved in $25 \mathrm{~mL}$ of isooctane/isopropanol (99:1, v/v). Tocopherols were determined using a Shimadzu LC-10 high-performance liquid chromatography system. The sample was first injected into a LiChrospher $\mathrm{Si}$ 60 column $(L=250 \mathrm{~mm}, \Phi=4.6 \mathrm{~mm}$ id, and $\emptyset=5 \mu \mathrm{m}$ film thickness), and then tocopherols were detected using an RF10AXL HPLC Fluorescence Detector (Shimadzu, Columbia, MD, USA) at an excitation wavelength of $290 \mathrm{~nm}$ and an emission of $330 \mathrm{~nm}$. The eluent used was a 99:1 isooctane/ isopropanol $(\mathrm{v} / \mathrm{v})$ mixture, and the flow rate was set at
$1.2 \mathrm{~mL} / \mathrm{min}$. The tocopherol standards $\alpha-, \beta-, \gamma-$, and $\delta$-tocopherols (Sigma-Aldrich, Madrid, Spain) and Argan oil samples were quantified simultaneously. The different compounds of tocopherol were identified by comparing the retention times with authentic standards and confirmed by extrapolating the peak area of the individual tocopherol to the pre-established specific tocopherol calibration curve.

2.5. Statistical Analyses. All statistical analyses were performed using IBM SPSS Statistics version 21 (IBM Corp., Armonk, NY, USA) and R software version 3.6.2 (R Foundation for Statistical Computing, Vienna, Austria). One-way analysis of variance (ANOVA) was performed followed by Tukey's post hoc test to determine the statistically significant differences between the means of tocopherol concentrations from different provenances 
$(p<0.05)$. Pearson's correlation heatmap was also assessed to determine the relationship between the geographical parameters and quantity of tocopherols. Furthermore, principal component analysis (PCA) was performed to study whether the means of those regions are significantly different. In addition, linear discriminant analysis (LDA) was applied for creating predictive models that maximize the discrimination of the predefined regions. The difference between means was normalized by a measure of the withinclass variability. The statistical significance of each discriminant function was evaluated by Wilk's lambda.

\section{Results and Discussion}

3.1. Physicochemical Quality Parameters. The oil content ranged between 50.94\% in Agadir and 55.67\% in Taroudant. The results obtained for the oil content are in agreement with the range obtained by Ait Aabd et al. [43] (51.83-57.50\%). The ANOVA followed by Tukey's post hoc test confirmed significant differences between Argan provenances. According to the Moroccan Normalization guidelines SNIMA 08.5.090 [20], Argan oils extracted belong to the extra virgin Argan oil category (Table 2). The lowest acidity value was found in Agadir (0.15\%). However, the highest value was detected in Safi (0.26\%). The spectrophotometric UV indices $K_{232}$ and $K_{270}$ ranged between 0.94 and 1.05 and 0.14 and 0.17 , respectively. Furthermore, the highest peroxide value was noticed in Sidi Ifni $\left(2.13 \mathrm{meq} \mathrm{O}_{2} / \mathrm{kg}\right.$ oil $)$ and lowest in Taroudant $\left(1.46 \mathrm{meq} \mathrm{O}_{2} / \mathrm{kg}\right.$ oil $)$. The overall quality parameters confirmed the high quality of Argan oil samples.

3.2. Tocopherols Composition. As shown in Figure 2, $\gamma$-tocopherol was found to be the predominant tocopherol in Argan oil, followed by $\alpha$-tocopherol and $\delta$-tocopherol ( $\gamma$-tocopherol $>\alpha$-tocopherol $\approx \delta$-tocopherol). $\gamma$-tocopherol represents $90 \%$ of the total tocopherols [44]. Compared to the literature, similar results were obtained for mechanically pressed unroasted Argan kernels from old trees [22]. The results showed that $\beta$-tocopherol is present in Argan oil but in very low concentrations. Generally, the results obtained in this study are similar to those of Taribak et al. [45]. It should be noted, however, that $\beta$-tocopherol has not been detected in any of the studied oils, which might be attributed to the extraction method [46]. The amounts of tocopherols established by the Moroccan 08.5.090 standard [20] for extra virgin Argan oil are $18-75 \mathrm{mg} / \mathrm{kg}$ for $\alpha$-tocopherol, $640-810 \mathrm{mg} / \mathrm{kg}$ for $\gamma$-tocopherol, $54-110 \mathrm{mg} / \mathrm{kg}$ for $\delta$-tocopherol, and $600-900 \mathrm{mg} / \mathrm{kg}$ for total tocopherol. All values were within the established limits, except for $\gamma$-tocopherol in the samples from Safi, Essaouira, Agadir, and Sidi Ifni, which exceeded $810 \mathrm{mg} / \mathrm{kg}$. These provinces presented the coastal Argan samples. Abbasi et al. [47] reported that the amount of tocopherols is strongly affected by abiotic stress, especially $\gamma$-tocopherol that has an important role in protecting polyunsaturated fatty acids from oxidation and consequently increasing the seeds' longevity [48]. The results obtained prove that the current standard does not reflect the real performance in terms of the concentration of tocopherols in Argan oil.
Considering the geographical origins, ANOVA revealed a high variability for the three tocopherol homologues. The highest total tocopherol content was found in Safi $(1,271.68 \mathrm{mg} / \mathrm{kg})$, followed by Agadir $(1,167.93 \mathrm{mg} / \mathrm{kg})$ and Sidi Ifni $(1,106.87 \mathrm{mg} / \mathrm{kg})$. These values were confirmed by the results obtained by Aithammou et al. [22] for the same extraction method and age of trees. The lowest value was obtained for the samples from Taroudant $(783.23 \mathrm{mg} / \mathrm{kg})$, although this value remains very important. Kharbach et al. [23] reported that the samples of Taroudant $(865 \mathrm{mg} / \mathrm{kg}$ of oil) have the lowest total tocopherol content, which is in line with the results obtained for the same region. The value of $\gamma$-tocopherol was found to range from $1,120.75 \mathrm{mg} / \mathrm{kg}$ of oil in Safi to $657.10 \mathrm{mg} / \mathrm{kg}$ of oil in Taroudant. This range agrees with other results in the literature: $700.30-1,068 \mathrm{mg} / \mathrm{kg}$ of oil [22], $664-802 \mathrm{mg} / \mathrm{kg}$ [23], $531-756 \mathrm{mg} / \mathrm{kg}$ oil [6], and $545.9-701.1 \mathrm{mg} / \mathrm{kg}$ oil [49]. The value of $\alpha$-tocopherol was found to range from $84.59 \mathrm{mg} / \mathrm{kg}$ in Taroudant to $48.72 \mathrm{mg} /$ $\mathrm{kg}$ in Safi, with both regions exhibiting the lowest and highest altitude (Table 1). The range of variability for $\delta$-tocopherol was found to be between $102.21 \mathrm{mg} / \mathrm{kg}$ of oil in Safi and $41.53 \mathrm{mg} / \mathrm{kg}$ of oil in Taroudant. These detected values are consistent with the interval found by Aithammou et al. [22] (36.42-132 mg/kg of oil) and Kharbach et al. [23] (58.55-104.36 mg/kg of oil). According to El Kharrassi et al. [14] compared to olive oil, Argan oil has the highest concentration of total and $\gamma$-tocopherols, whereas the highest concentration of $\alpha$-tocopherol was observed in olive oil. In addition, Gharby et al. [50] mentioned that Argan oil has the highest concentration of $\alpha$-and $\delta$-tocopherols compared to cactus pear seed oil. As reported by Górnaś et al. [29], biotic factors (genotype) also affect the content of tocopherols in fruit kernel oils, such as apple cultivars (Malus domestica Borkh.), plums (Prunus domestica L.), and apricots (Prunus armeniaca L.). However, Dolde, Vlahakis, and Hazebrock [51] reported that the composition of tocopherols in oil seeds, such as sunflower and soybean, is highly dependent on environmental conditions rather than on genetic factors.

3.3. Relation between Geographical Parameters and Tocopherols. Pearson's correlation analysis (Figure 3) revealed that the longitude, minimum temperature, and rainfall have no effect on the tocopherol content. However, distance from the coast was found to exhibit a strong positive correlation with $\alpha$-tocopherol and a strong negative correlation with $\gamma$-tocopherol, $\delta$-tocopherol, and total tocopherols (correlation is significant at the 0.01 level). A significant correlation was also found between altitude and tocopherol homologues. Although latitude was found to have a significant negative correlation with $\gamma$-tocopherol and total tocopherol, a significant positive correlation was observed with $\alpha$-tocopherol. The maximum temperature was also found to have a significant correlation with $\alpha$-tocopherol. The geographical origin can affect the process of producing effective substances, especially in climatic conditions [52]. To date, few studies have been conducted to investigate the interaction between climatic parameters and tocopherol content in Argan oil. However, levels of 
TABLE 2: Mean values and standard deviations of the oil content and quality parameters of Argan oil from six provenances.

\begin{tabular}{|c|c|c|c|c|c|c|c|}
\hline Provenance & Safi & Essaouira & Agadir & Taroudant & Tiznit & Sidi Ifni & $\begin{array}{l}\text { SNIMA } \\
08.5 .090\end{array}$ \\
\hline Oil c & & & & & $a$ & $5 b$ & - \\
\hline Free & & & & & & & $\leq 0.8$ \\
\hline$K_{232}$ & $7 a$ & $0.94 \pm$ & $0.05 a$ & 1.03 & 0.98 & $07 a$ & $\leq 2.52$ \\
\hline$K_{270}$ & $.03 a$ & $.02 a$ & $.03 a$ & $.01 a$ & $.02 a$ & $02 a$ & $\leq 0.35$ \\
\hline Peroxyde value (meq $\mathrm{O} 2 / \mathrm{kg}$ oil) & $1.68 \pm 0.06 a b$ & $1.57 \pm 0.13 a$ & $1.97 \pm 0.06 c d$ & $1.46 \pm 0.04 a$ & $1.83 \pm 0.08 b c$ & $2.13 \pm 0.07 d$ & $\leq 15$ \\
\hline
\end{tabular}

Values are expressed as mean \pm SD. Different letters in the same line designate significant differences $(p<0.05) . K_{232}$ and $K_{270}$ : ultra violet specific extinction at 232 and $270 \mathrm{~nm}$, respectively.

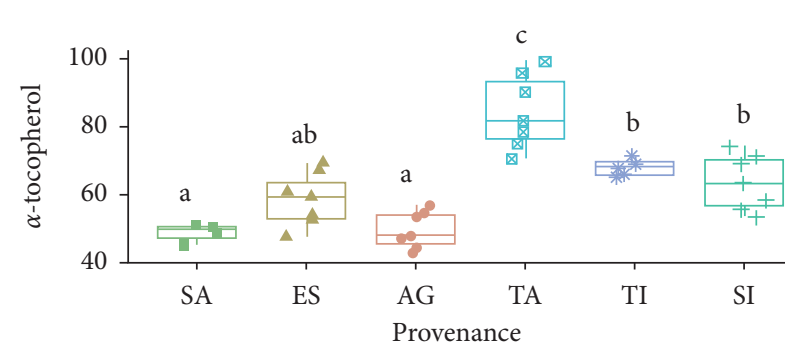

(a)

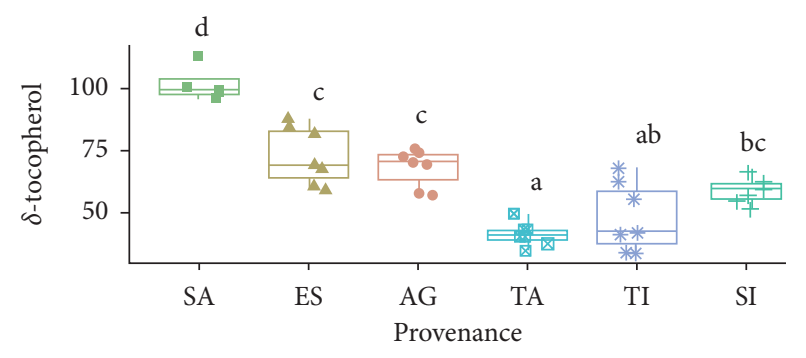

(c)

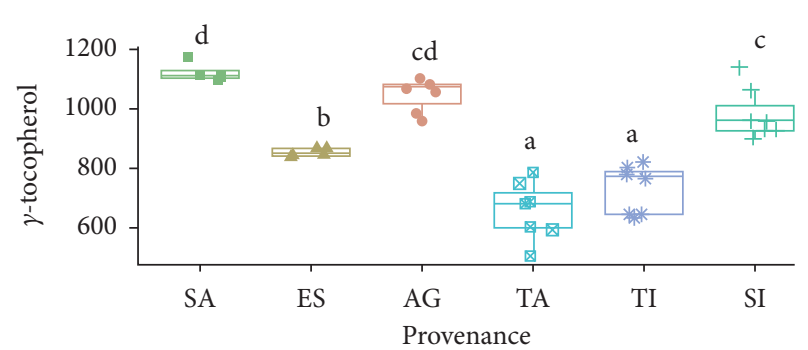

(b)

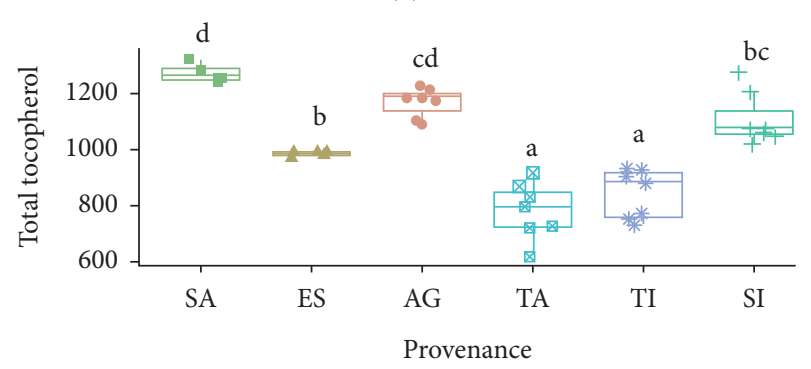

(d)

Figure 2: Boxplot of: (a) $\alpha$-tocopherol, (b) $\gamma$-tocopherol, (c) $\delta$-tocopherol, and (d) total to copherolin argan oil samples collected in different provinces (Safi: SA, Essaouira: ES, Agadir: AG, Taroudant: TA, Tiznit: TI, and Sidi Ifni: SI). Significant differences $(p<0.05)$ were expressed by different letters.

$\gamma$-tocopherol increased with average temperature and total sunshine and decreased with total rainfall in flaxseed oil [53]. The total tocopherol of olive oil is also strongly affected by altitude [54]. Other Argan oil compounds such as fatty acids were influenced by altitude, latitude, and longitude $[37,43,55]$.

3.4. Principal Compound Analysis (PCA). Figure 4 shows a score PCA plot for the 39 Argan oil samples obtained from six provenances according to their tocopherol composition. The first two principal components were found to be very significant, explaining $93 \%$ of the total inertia. Although PC1 (Dim1) presented $81.8 \%$ of the total inertia, PC2 (Dim2) presented $11.2 \%$. PC1 allowed classifying the coastal sampled locations on the left side of PCA. However, the most continental sampled provinces were plotted on the right side. On the one hand, the coastal locations were characterized by high concentrations of $\gamma$-tocopherol, $\delta$-tocopherol, and total tocopherols. On the other hand, $\alpha$-tocopherol was the most remarkable tocopherol homologue in continental Argan oil samples. Hence, it can be concluded that $\gamma$-tocopherol could be used as a good marker of coastal Argan oils. In addition, $\alpha$-tocopherol can be used as a marker of the continental provinces. The geographical origin has a high impact on tocopherols concentration, showing a distinction between the different studied provenances. This easy, rapid, and precise technique can be used by laboratories to protect this precious oil from fraud such as adulteration by other cheaper oils. Furthermore, it can be combined with other analyses such as fatty acids and phytosterol to enhance the protected geographical indication (PGI).

3.5. Linear Discriminant Analysis (LDA). LDA is a supervised method contrarily to PCA. It was performed to create discriminant models for the classification of Argan oil according to their geographical origin. Figure 5 shows the LDA scatter plot for Argan oils from six provinces. The most continental provinces were plotted on the left of function 1, whereas the coastal origins are plotted on the right. A distinct separation between the provinces was relevant, with some overlap, notably between Tiznit and Taroudant, which can be explained by the geographical parameter similarities. 


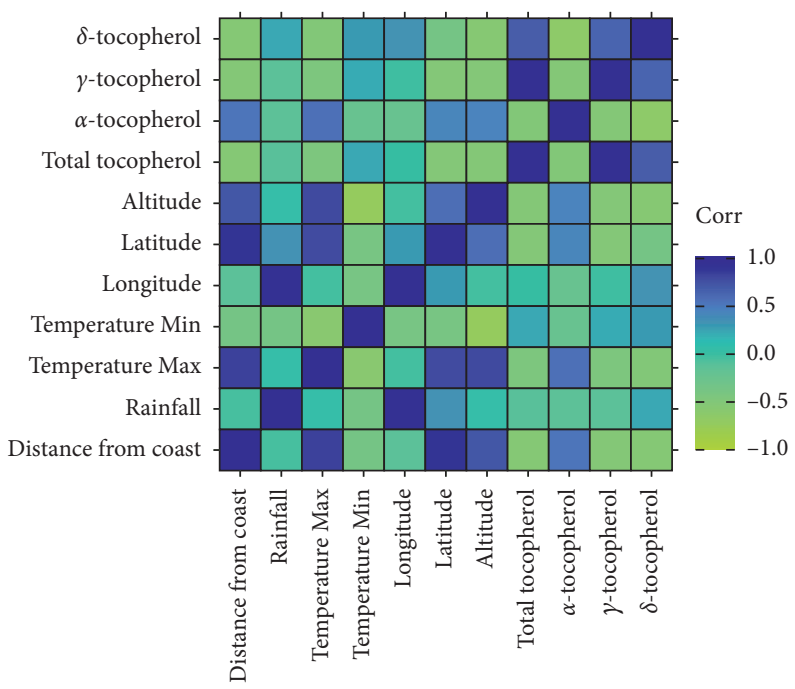

FIgURE 3: Heatmap of Pearson's correlation coefficient between tocopherol homologues and geographical parameters.

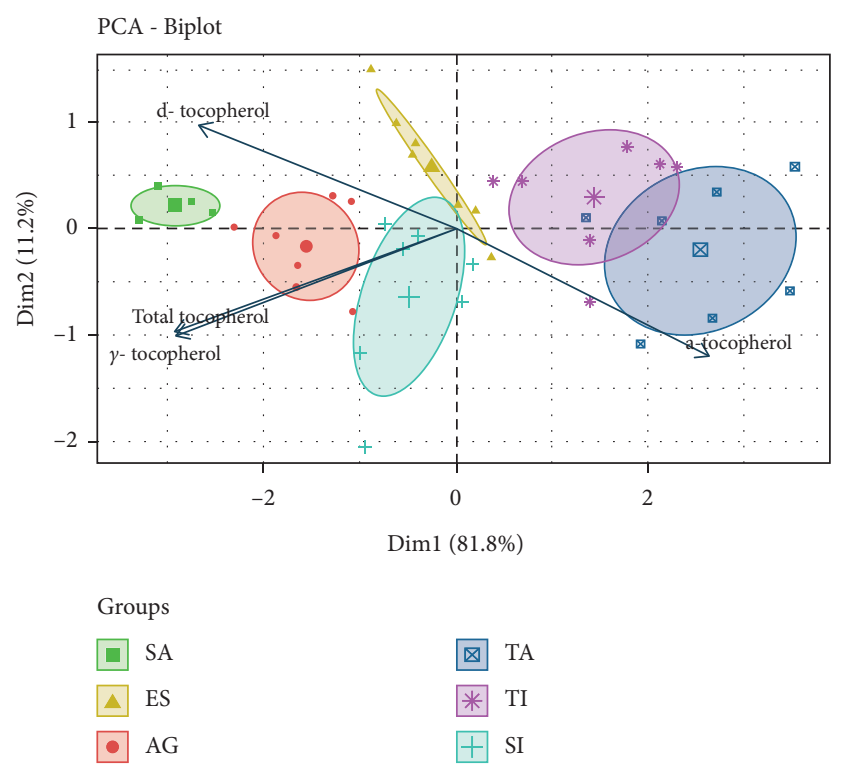

FIGURe 4: Principal component analysis (PCA) on the tocopherols amount of 39 samples from six different provenances (SA: Safi, ES: Essaouira, AG: Agadir, SI: Sidi Ifni, TA: Taroudant, and TI: Tiznit).

Table 3 presented three discriminant functions created based on Wilks' lambda values, which explained $100 \%$ of the variance (Table 3); $85.7 \%$ of the total variance was explained by function $1,10.7 \%$ explained by function 2 , and $3.6 \%$ explained by function 3. The Wilks' lambda values (Table 3) for the functions 1,2 , and 3 were $0.02,0.30$, and 0.69 , respectively, with $p$-values $0.0001,0.0001$, and 0.007 . The LDA showed a good predictive ability, which can reach up to $87.2 \%$ for the geographical origin classification.

Discriminant models allowed a good prediction with an accuracy of $87.2 \%$ (Table 4). Essaouira, Safi, and Sidi Ifni presented the highest correct classification rate $(100 \%)$ followed by Agadir (85.71\%). Taroudant and Tiznit presented the lowest classification rate $(71.42 \%)$. According to the results obtained by Elgadi et al. [37] using the LDA
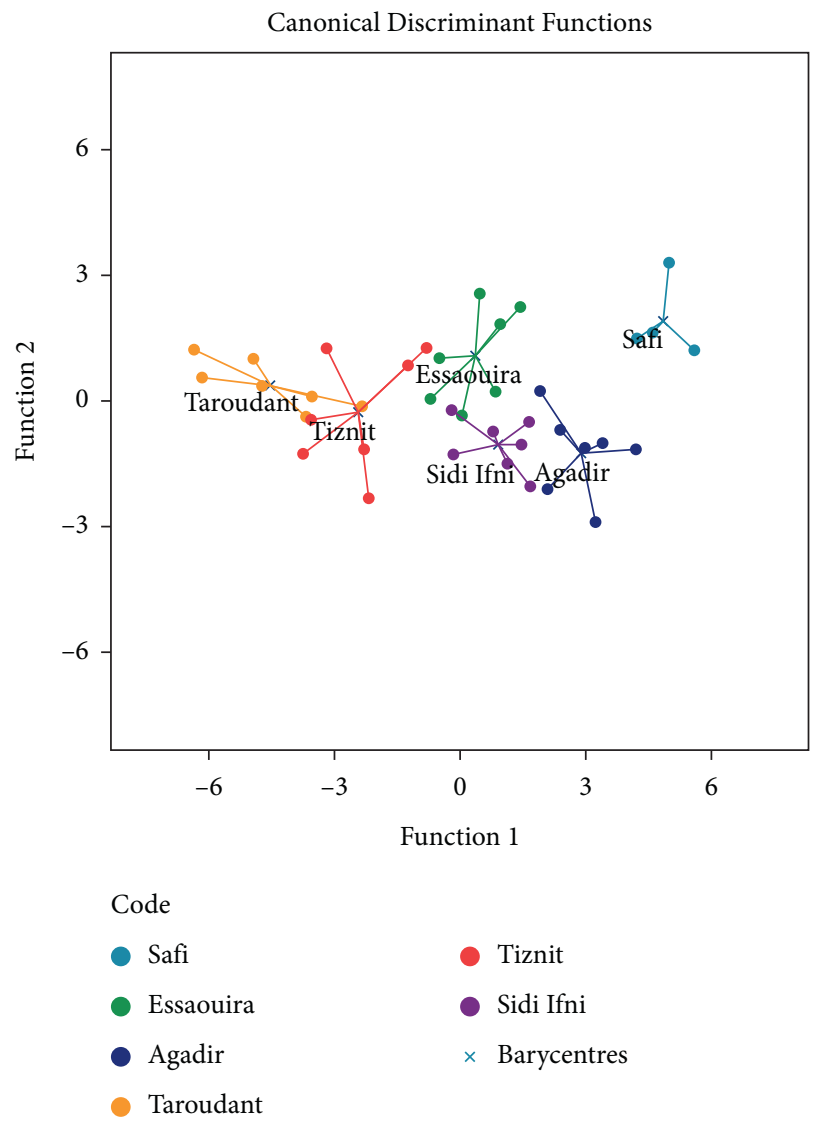

FIGURE 5: Linear discriminant analysis based on the tocopherols amount of 39 samples from six different provenances.

models based on fatty acids and isotope combination, the classification rate fluctuate between $85.7 \%$ and $100 \%$, which was near to the obtained accuracy. Furthermore, the results obtained by Miklavčič et al. [56] based on fatty acid profile using OPLS-DA showed a similar rate $(82 \%-100 \%)$. The high accuracy confirms the performance of tocopherols in the prediction of geographical origin. 
TABLE 3: Discriminant functions elaborated based on the tocopherols composition.

\begin{tabular}{|c|c|c|c|c|c|}
\hline Functions & $\begin{array}{l}\text { Wilks' } \\
\text { lambda }\end{array}$ & $p$ value & Variance (\%) & Cumulative (\%) & $\begin{array}{l}\text { Canonical } \\
\text { correlation }\end{array}$ \\
\hline $\begin{array}{l}\text { Function } 1=-0.70-0.07 \times \alpha \text {-tocopherol }+0.01 \times \gamma \text { - } \\
\text { tocopherol }+0.035 \times \delta \text {-tocopherol }\end{array}$ & 0.02 & 0.000 & 85.7 & 85.73 & 0.95 \\
\hline $\begin{array}{l}\text { Function } 2=-4.33+0.05 \times \alpha \text {-tocopherol }-0.01 \times \gamma \text {-tocopherol }+0.11 \times \delta \text { - } \\
\text { tocopherol }\end{array}$ & 0.30 & 0.000 & 10.7 & 96.42 & 0.75 \\
\hline $\begin{array}{l}\text { Function } 3=-14.36+0.11 \times \alpha \text {-tocopherol }+0.01 \times \gamma \text { - } \\
\text { tocopherol }+0.01 \times \delta \text {-tocopherol }\end{array}$ & 0.69 & 0.007 & 3.6 & 100.00 & 0.55 \\
\hline
\end{tabular}

TABLE 4: Performance of the LDA classification models for the geographical origin prediction.

\begin{tabular}{|c|c|c|c|c|c|c|}
\hline \multirow{2}{*}{ Provenance of origin } & \multicolumn{6}{|c|}{ Predicted origin } \\
\hline & Agadir & Essaouira & Safi & Sidi Ifni & Taroudant & Tiznit \\
\hline Agadir & $6(85.71 \%)$ & $1(14.28 \%)$ & 0.0 & 0.0 & 0.0 & 0.0 \\
\hline Essaouira & 0.0 & $7(100 \%)$ & 0.0 & 0.0 & 0.0 & 0.0 \\
\hline Safi & 0.0 & 0.0 & $4(100 \%)$ & 0.0 & 0.0 & 0.0 \\
\hline Sidi Ifni & 0.0 & 0.0 & 0.0 & $7(100 \%)$ & 0.0 & 0.0 \\
\hline Taroudant & 0.0 & 0.0 & 0.0 & 0.0 & $5(71.42 \%)$ & $2(28.57 \%)$ \\
\hline Tiznit & 0.0 & $2(28.57 \%)$ & 0.0 & 0.0 & 0.0 & $5(71.42 \%)$ \\
\hline
\end{tabular}

\section{Conclusion}

The results obtained in this study highlight the impact of the geographical origin on the $\alpha$-tocopherol, $\gamma$-tocopherol, and $\delta$-tocopherol content. Pearson's correlation analysis showed that the longitude, minimum temperature, and rainfall have no effect on the content of tocopherols. However, distance from the coast, latitude, and altitude was found to exhibit a strong correlation with the majority of tocopherol homologues. PCA also revealed a distinction between provenances and confirmed the relationship between the geographical origin and tocopherol concentration. In addition, $\alpha$-tocopherol and $\gamma$-tocopherol could present promising markers to protect the geographical origin of Argan oil. The prediction ability of the LDA models was $87.2 \%$. Our study provided interesting results for the variability of tocopherol homologues concentration in six principal production areas. This technique is easy, not expensive, and rapid for laboratories to control the fraud related to geographical origin. These results present a preliminary basis for determining the geographical origins of Argan oil and highlight the real tocopherols potential in Argan oil that varies from $1,271.68$ to $844.05 \mathrm{mg} / \mathrm{kg}$ of oil. Further future studies more exhaustive are planned to confirm the obtained results. In addition, more studies focussing on biotic factors (genotype/variety/cultivar) are necessary to have a clear overview of tocopherol homologues variation, which is very useful particularly for varietal selection objectives.

\section{Data Availability}

The data used to support the findings of this study are available from the corresponding author upon request.

\section{Conflicts of Interest}

The authors declare that they have no conflicts of interest.

\section{Acknowledgments}

The authors are very grateful to the ANDZOA and GIZ for assistance in the choice of sampling sites and facilitation of contact with the cooperative. Thanks are due to Women's Cooperative Tighanimine Filahia (Agadir), for Argan fruit processing. The authors are grateful to the staff of the laboratory for chemical analysis, especially $\mathrm{Mr}$. M. Amakhmakh, and the staff of the laboratory of AgroFood Technology and Quality (INRA-Marrakech).

\section{References}

[1] F. Msanda, A. El Aboudi, and J.-P. Peltier, "Biodiversité et biogéographie de l'arganeraie marocaine," Agriculture and Forestry, vol. 14, no. 4, pp. 357-364, 2005.

[2] S. Elgadi, A. Ouhammou, H. Zine, N. Maata, R. Ait Babahmad, and A. El Antari, "Comparative oil composition study of the endemic Moroccan olive (Olea europaea subsp. maroccana) and wild olive (Var. sylvestris) in central west Morocco," Journal of Food Quality, vol. 2021, Article ID 8869060, 10 pages, 2021.

[3] Z. Charrouf and D. Guillaume, "Argan oil, the 35-years-ofresearch product," European Journal of Lipid Science and Technology, vol. 116, no. 10, pp. 1316-1321, 2014.

[4] Z. Charrouf and D. Guillaume, "Argan oil: occurrence, composition and impact on human health," European Journal of Lipid Science and Technology, vol. 110, no. 7, pp. 632-636, 2008.

[5] M. Jordan, A. Nayel, B. Brownlow, and T. Elbayoumi, "Development and evaluation of tocopherol-rich argan oil-based nanoemulsions as vehicles possessing anticancer activity," Journal of Biomedical Nanotechnology, vol. 8, no. 6, pp. 944-956, 2012.

[6] S. Gharby, H. Harhar, H. El Monfalouti et al., "Chemical and oxidative properties of olive and argan oils sold on the Moroccan market. A comparative study," Mediterranean Journal of Nutrition and Metabolism, vol. 5, no. 1, pp. 31-38, 2012. 
[7] M. Hilali, Z. Charrouf, A. E. A. Soulhi, L. Hachimi, and D. Guillaume, "Detection of argan oil adulteration using quantitative campesterol GC-analysis," Journal of the American Oil Chemists' Society, vol. 84, no. 8, pp. 761-764, 2007.

[8] M. Dietrich, M. G. Traber, P. F. Jacques, C. E. Cross, Y. Hu, and G. Block, "Does $\gamma$-tocopherol play a role in the primary prevention of heart disease and Cancer? a review," Journal of the American College of Nutrition, vol. 2, no. 5, pp. 37-41, 2006.

[9] L. Dugo, M. Russo, F. Cacciola et al., "Determination of the phenol and tocopherol content in Italian high-quality extravirgin olive oils by using LC-MS and multivariate data analysis," Food Analytical Methods, vol. 13, no. 5, pp. 1027-1041, 2020.

[10] S. Marubayashi, K. Dohi, K. Sugino, and T. Kawasaki, "The protective effect of administered $\alpha$-Tocopherol against hepatic damage caused by ischemia-reperfusion or endotoxemia," Annals of the New York Academy of Sciences, vol. 570, no. 1 Vitamin E, pp. 208-218, 1989.

[11] A. El Abbassi, N. Khalid, H. Zbakh, and A. Ahmad, "Physicochemical characteristics, nutritional properties, and health benefits of argan oil: a review," Critical Reviews in Food Science and Nutrition, vol. 54, no. 11, pp. 1401-1414, 2014.

[12] A. Durazzo, A. Nazhand, M. Lucarini et al., "Occurrence of tocols in foods: an updated shot of current databases," Journal of Food Quality, vol. 2021, Article ID 8857571, 7 pages, 2021.

[13] A. Rueda, C. Samaniego-Sánchez, M. Olalla et al., "Combination of analytical and chemometric methods as a useful tool for the characterization of extra virgin argan oil and other edible virgin oils. Role of polyphenols and tocopherols," Journal of AOAC International, vol. 99, no. 2, pp. 489-494, 2016.

[14] Y. El Kharrassi, N. Maata, M. A. Mazri et al., "Chemical and phytochemical characterizations of argan oil (Argania spinosa L. Skeels), olive oil (Olea europaea L. cv. Moroccan picholine), cactus pear (Opuntia megacantha salm-dyck) seed oil and cactus cladode essential oil," Journal of Food Measurement and Characterization, vol. 12, no. 2, pp. 747-754, 2018.

[15] C. Cabrera-Vique, R. Marfil, R. Giménez, and O. MartínezAugustin, "Bioactive compounds and nutritional significance of virgin argan oil-an edible oil with potential as a functional food," Nutrition Reviews, vol. 70, no. 5, pp. 266-279, 2012.

[16] A. Delgado, S. Al-Hamimi, M. F. Ramadan et al., "Contribution of tocols to food sensorial properties, stability, and overall quality," Journal of Food Quality, vol. 2020, Article ID 8885865, 8 pages, 2020.

[17] H. El Monfalouti, D. Guillaume, C. Denhez, and Z. Charrouf, "Therapeutic potential of argan oil: a review," Journal of Pharmacy and Pharmacology, vol. 62, no. 12, pp. 1669-1675, 2010.

[18] F. Khallouki, C. Younos, R. Soulimani et al., "Consumption of argan oil (Morocco) with its unique profile of fatty acids, tocopherols, squalene, sterols and phenolic compounds should confer valuable cancer chemopreventive effects," European Journal of Cancer Prevention, vol. 12, no. 1, pp. 67-75, 2003.

[19] A. Drissi, "Evidence of hypolipemiant and antioxidant properties of argan oil derived from the argan tree (Argania spinosa)*1," Clinical Nutrition, vol. 23, no. 5, pp. 1159-1166, 2004.

[20] 2003 SNIMA 08.5.090, "Service de Normalisation Industrielle Marocaine (SNIMA) Huiles d'argane," Specif. Norme marocaine NM 08.5.090 Rabat.
[21] S. Gharby, H. Harhar, D. Guillaume, A. Haddad, and Z. Charrouf, "The origin of virgin argan oil's high oxidative stability unraveled," Natural Product Communications, vol. 7, no. 5, pp. 621-624, 2012.

[22] R. Aithammou, C. Harrouni, L. Aboudlou et al., "Effect of clones, year of harvest and geographical origin of fruits on quality and chemical composition of Argan oil," Food Chemistry, vol. 297, Article ID 124749, 2019.

[23] M. Kharbach, R. Kamal, M. Bousrabat et al., "Characterization and classification of PGI Moroccan Argan oils based on their FTIR fingerprints and chemical composition," Chemometrics and Intelligent Laboratory Systems, vol. 162, pp. 182-190, 2017.

[24] P. Górnaś, M Rudzińska, M Raczyk et al., "Impact of species and variety on concentrations of minor lipophilic bioactive compounds in oils recovered from plum kernels," Journal of Agricultural and Food Chemistry, vol. 64, no. 4, pp. 898-905, 2016.

[25] M. Hilali, Z. Charrouf, A. E. Aziz Soulhi, L. Hachimi, and D. Guillaume, "Influence of origin and extraction method on argan oil physico-chemical characteristics and composition," Journal of Agricultural and Food Chemistry, vol. 53, no. 6, pp. 2081-2087, 2005.

[26] S. Gharby, H. Harhar, D. Guillaume, A. Haddad, B. Matthäus, and Z. Charrouf, "Oxidative stability of edible argan oil: a twoyear study," LWT-Food Science and Technology, vol. 44, no. 1, pp. 1-8, 2011.

[27] S. Gharby, H. Harhar, B. E. Kartah et al., "Can fruit-form be a marker for Argan oil production?” Natural Product Communications, vol. 8, no. 1, pp. 25-28, 2013.

[28] H. Harhar, S. Gharby, B. Kartah, D. Pioch, D. Guillaume, and Z. Charrouf, "Effect of harvest date of Argania spinosa fruits on Argan oil quality," Industrial Crops and Products, vol. 56, pp. 156-159, 2014.

[29] P. Górnaś, E. Radziejewska-Kubzdela, I. Mišina, R. BiegańskaMarecik, A. Grygier, and M. Rudzińska, "Tocopherols, tocotrienols and carotenoids in kernel oils recovered from 15 apricot (Prunus armeniaca L.) genotypes," Journal of the American Oil Chemists Society, vol. 94, no. 5, pp. 693-699, 2017.

[30] P. Górnaś, "Unique variability of tocopherol composition in various seed oils recovered from by-products of apple industry: rapid and simple determination of all four homologues $(\alpha, \beta, \gamma$ and $\delta$ ) by RP-HPLC/FLD," Food Chemistry, vol. 172, pp. 129-134, 2015.

[31] O. Pakhrou, L Medraoui, B Belkadi et al., "Using two retrotransposon-based marker systems (SRAP and REMAP) for genetic diversity analysis of Moroccan argan tree," Molecular Biology Research Communications, vol. 9, no. 3, pp. 93-103, 2020.

[32] J.-P. Peltier, "Les séries de l'arganeraie steppique dans le Sous (Maroc)," Ecologia Mediterranea, vol. 9, no. 1, pp. 77-88, 1983.

[33] B. Fady and F. Médail, "Mediterranean forest ecosystems," in Encyclopedia of Forest Science, J. Burley, J. Evans, and J. A. Youngquist, Eds., pp. 1403-1414, Elsevier, London, UK, 2004.

[34] M. F. Ramadan, "Healthy blends of high linoleic sunflower oil with selected cold pressed oils: functionality, stability and antioxidative characteristics," Industrial Crops and Products, vol. 43, no. 1, pp. 65-72, 2013.

[35] 2021 Argan Oil Market Size, Share \& Trends Analysis Report by Type (Conventional, Organic), by Form (Absolute, Concentrate, Blend), by Application, by Distribution Channel, by Region, and Segment Forecasts, 2020-2027. 
[36] R. Consonni and L. R. Cagliani, "Nuclear magnetic resonance and chemometrics to assess geographical origin and quality of traditional food products," Advances in Food and Nutrition Research, vol. 59, pp. 87-165, 2010.

[37] S. Elgadi, A. Ouhammou, F. Taous et al., "Combination of stable isotopes and fatty acid composition for geographical origin discrimination of one argan oil vintage," Foods, vol. 10, no. 6, pp. 1-13, 2021.

[38] ISO 660, Animal and Vegetable Fats and Oils-Determination of Acid Value and Acidity, Polish Communist Standardization, Warsaw, Poland, 2009.

[39] ISO 3656, Animal and Vegetable Fats and Oils-Determination of Ultraviolet Absorbance Expressed as Specific UV Extinction, International Organization for Standardization, Geneva, Switzerland, 2002.

[40] ISO 3960, Animal and Vegetable Fats and Oils-Determination of Peroxide Value-Iodometric (Visual) Endpoint Determination, International Organization Standardization BSI Standardization, London, UK, 2007.

[41] ISO 659, Oilseeds-Determination of Oil Content (Reference Method), International Organization for Standardization, Geneva, Switzerland, 2009.

[42] ISO 9936, Animal and Vegetable Fats and Oils-Determination of Tocopherols and Tocotrienols Contents-Method Using High Performance Liquid Chromatography, 2016.

[43] N. Ait Aabd, A. El Asbahani, Y. El Alem, A. El Finti, F. Msanda, and A. El Mousadik, "Variation in oil content and fatty acid composition in preselected argan trees with morphological characters and geographical localization," Mediterranean Journal of Nutrition and Metabolism, vol. 6, no. 3, pp. 217-225, 2013.

[44] M. LucarinI, A. Durazzo, and S. F. Nicoli, "Cold pressed argan (Argania spinose) oil," in Cold Pressed Oils, pp. 459-465, Academic Press, Cambridge, MA, USA, 2020.

[45] C. Taribak, L. Casas, C. Mantell, Z. Elfadli, R. E. Metni, and E. J. Martínez De La Ossa, "Quality of cosmetic argan oil extracted by supercritical fluid extraction from Argania spinosa L," Journal of Chemistry, vol. 2013, Article ID 408194, 9 pages, 2013.

[46] R. Marfil, R. Giménez, O. Martínez et al., "Determination of polyphenols, tocopherols, and antioxidant capacity in virgin argan oil (Argania spinosa, Skeels)," European Journal of Lipid Science and Technology, vol. 113, no. 7, pp. 886-893, 2011.

[47] A.-R. Abbasi, M. Hajirezaei, D. Hofius, U. Sonnewald, and L. M. Voll, "Specific roles of $\alpha$ - and $\gamma$-tocopherol in abiotic stress responses of transgenic tobacco," Plant Physiology, vol. 143, no. 4, pp. 1720-1738, 2007.

[48] S. E. Sattler, L. U. Gilliland, M. Magallanes-Lundback, M. Pollard, and D. DellaPenna, "Vitamin E is essential for seed longevity and for preventing lipid peroxidation during germination," The Plant Cell Online, vol. 16, no. 6, pp. 1419-1432, 2004.

[49] M. Hilali, H. El Monfalouti, and B. E. Kartah, "Evaluation of the chemical composition of Argan (Argania spinosa L.) oil according to its extraction method, origin of production and altitude," Journal of World's Poultry Research, vol. 10, no. 3, pp. 111-118, 2020.

[50] S. Gharby, D. Guillaume, I. Nounah et al., "Shelf-life of Moroccan prickly pear (Opuntia ficus-indica) and argan (Argania spinosa) oils: a comparative study," Grasas Y Aceites, vol. 72, no. 1, pp. 1-9, 2021.

[51] D. Dolde, C. Vlahakis, and J. Hazebroek, "Tocopherols in breeding lines and effects of planting location, fatty acid composition and temperature during development," Journal of the American Oil Chemists' Society, vol. 76, no. 3, pp. 349-355, 1999.

[52] Z. Zargoosh, M. Ghavam, G. Bacchetta, and A. Tavili, "Effects of ecological factors on the antioxidant potential and total phenol content of Scrophularia striata Boiss," Scientific Reports, vol. 9, no. 1, pp. 16021-16115, 2019.

[53] M. Obranović, D Škevin, K Kraljić et al., "Influence of climate, variety and production process on tocopherols, plastochromanol-8 and pigments in flaxseed oil," Food Technology and Biotechnology, vol. 53, no. 4, pp. 496-504, 2015.

[54] R. Mafrica, A. Piscopo, A. De Bruno, and M. Poiana, "Effects of climate on fruit growth and development on olive oil quality in cultivar carolea," Agriculture and Forestry, vol. 11, no. 2, pp. 1-18, 2021.

[55] M. Kharbach, R. Kamal, I. Marmouzi et al., "Fatty-acid profiling vs UV-Visible fingerprints for geographical classification of Moroccan Argan oils," Food Control, vol. 95, 2019.

[56] M. B. Miklavčič, F Taous, V Valenčič et al., "Fatty acid composition of cosmetic argan oil: provenience and authenticity criteria," Molecules (Basel, Switzerland), vol. 2518 pages, 2020. 